\title{
INTERPRETING USERS' EXPERIENCES OF SERVICE DELIVERY IN THE WESTERN CAPE USING A NORMATIVE FRAMEWORK
}

\section{Vivienne Bozalek \& Wesley Lambert}

\section{INTRODUCTION}

The South African government recognises its role in delivering services for addressing poverty and does so through social security and social development programmes based in different service delivery organisations (White Paper for Social Welfare, 1997). The importance of ascertaining the views of social service users is becoming more prevalent in human service delivery and has been established particularly in the fields of mental health and disability and in the new social movements (Beresford \& Croft, 2004). For example, in the United Kingdom service users are increasingly participating in the education, training and assessment of social work students, in research and in wider decision making, such as participation in social policy development (Beresford, Page \& Stevens, 1994; Cornwall \& Gaventa, 2001a; Hanley, 2005; Joans \& Gaventa, 2002; Levin, 2004). Over the past two decades new legislation has made the participation of service users a requirement in the planning and development of services; however, it has been found that exclusionary structures within organisations, institutional practices and professional attitudes affect the extent to which change can by achieved by service users (Carr, 2007).

This particular case study focuses on the current status of transformed service delivery as viewed and experienced by service users. Drawing on data collected by students at a higher education institution in the Western Cape, the authors illustrate how a normative framework can be used to deepen understanding of service users' experiences and expectations of adequacy of service delivery by social service professionals. This normative framework is drawn from three major sources - Tronto's (1993) political care ethic, Fraser's (1989) juridical-administrativetherapeutic needs interpretation politics and Everitt and Hardiker's (1996) "good enough practice" model.

\section{Fraser's juridical-administrative-therapeutic procedures}

As service users enter the public space they inadvertently become embroiled in the administrative processes and procedures of care in social service delivery (Skidmore, 1994). Caring in bureaucracies is supported by administrative procedures in order to provide effective services, for example, in the arena of social security. Therefore, social workers and administrative personnel are both frontline operators who interpret service users' needs according to rigid administrative procedures. The American political theorist, Nancy Fraser (1989:154), describes this as a distinctive style of operating in service delivery and refers to the system as "the juridical-administrative-therapeutic state apparatus" (JAT). This apparatus operates according to, and works in practice by linking together, the juridical-administrative-therapeutic procedures. The juridical element refers to service users' welfare rights, which can be condoned or denied depending on the interpretation of the need and benefit claimed. This element then links with the administrative element in which service users have to petition their needs to an administrative body. It is only this body which is empowered to decide on whether service users' claims meet administratively defined criteria or not. The modus operandi which then follows is the therapeutic element when social workers concern themselves with interpreting these needs as mental health and behavioural issues which require intervention in service users' lives. As a result the welfare system executes political policy that in practice appears to be non-political (Fraser, 1989:154). 
Fraser (1989:145) contends that social welfare issues are posed in terms of how and to what degree the state should undertake to address the social needs of even the poorest of the poor. According to Fraser (1989), welfare policy assumes that needs are self-evident and without dispute rather than being socially constructed and open to interpretation. In contrast to this, Fraser (1989:156) sees the "social" as a site of discourse about people's needs, specifically about problematic needs which have broken out of the domestic and/or official economic spheres that earlier contained them as "private matters". In this terrain of the "social", Fraser identifies a number of competing discourses or ways of talking about such problematic needs. One is the needs discourse of experts - for example, social service workers, whose raison d'être is to intervene in a situation defined as problematic. A second discourse identified by Fraser (1989) is the oppositional needs discourse in which social movements or service users articulate their views. Such a discourse subverts official discourses in that it reflects the voices of those "from below", as Fraser (1989:171) puts it.

Thus she labels her approach the "politics of needs interpretation" where needs are seen as contested rather than given. This alerts us to pay attention to who is constructing service users' needs and in what context they are being constructed.

\section{Tronto's political ethic of care}

In South Africa professional responsibility in service delivery is governed by Professional Codes of Conduct and encompasses the Batho Pele principles as principle ethics for good practice. Batho Pele (meaning "people first") is the South African government's initiative to improve the delivery of integrated (formerly segregated) public services to all South Africans. "People first" ensures that attitudes, systems and procedures are reoriented in favour of service delivery requiring all staff to act in the best interests of the service users (White Paper, Transformation of Public Service Delivery, 1997).

The political ethic of care as proposed by Joan Tronto (1993) is a more extended form of professional accountability which can be seen to build upon Batho Pele principles. Tronto's (1993) argument for a political ethic of care rests upon the notion of the interdependent nature of human life with corresponding reciprocal relations between parties. She contests the individualistic notion of human beings critiquing society's economic ideology of "self-made man", which is the dominant doxa or prevalent perception upon which much social service policy and activity is premised (albeit at subliminal level). Individualism and autonomy are problematised in the care ethic, because self-made individuals neither admit to how care makes their lives possible nor will they undermine the unequal distribution of power, resources and privileges they accrue to themselves as benefits (Tronto, 1993:111). Her argument is important for the social welfare system as this notion of "self-reliance" is the premise upon which South African social policy is based.

The significance in motivating the political ethic of care as a normative paradigm from which to judge the adequacy of service users' experiences of service delivery is that it takes into account the construction of the "other" (service user) in considering his/her own need for care. According to Fraser (1989), needs are not givens but are politically contested, so various views of need are in competition with each other, for example, that of the professional expert and that of the service user. In Tronto's (1993:108) words, “what is definitive about care ... [is] a perspective of taking the other's need as the starting point for what must be done". This perspective of social relations within the context of care in service delivery is useful in that it alerts us to "consider the position of the care-receivers from their perspective" (Barnes, 2006:120). 
Tronto (1993) views care as an "ongoing practice" consisting of four inter-related phases, namely, "caring about", "taking care of", "care giving" and "care receiving". Each of these phases is underpinned by four corresponding values: attentiveness (recognising that needs exist), responsibility (acting on needs), competence (having resources to address needs) and responsiveness (how well needs are addressed). Responsiveness as a key element in the care process informs us how well needs are met, but it is reliant on attentiveness, which in turn requires responsibility and competence (Barnes, 2006; Tronto 1993). The inter-relation of these four phases and corresponding values forms the integrity of the care ethic, which Sarah Banks (2006) has recently proposed as a fifth element in the care process. Tronto $(1993: 109,110,136)$ recognised that the integrity of care is based on the integrated phases and moral values constituting care as practice, as it is "the standard for an integrated, well accomplished act of care". Integrity of care serves as "standard" by which to judge care's adequacies as "morally admirable" (Tronto 1993:136). Tronto (1993) recognises that there are many needs that require care and this creates a moral dilemma for care practices. Despite this, it is important to make adequate decisions as to how best to meet caring responsibilities.

\section{Everitt and Hardiker's good practice}

In order to judge the adequacy of service delivery, it is useful, in addition to the political ethics of care perspective and the politics of needs interpretation, to consider what could constitute "good practice". Everitt and Hardiker (1996:1, 27-28) suggest "good practice" as an alternative approach to social control evaluation measures with which to evaluate how service delivery practices best meet caring responsibilities from services users' perspectives. Their approach to evaluation is similar to the political ethic of care in that it values the democratic communication and interaction process between service user and social worker, i.e. responsiveness as following from attentiveness, responsibility and competence.

One other purpose of "good practice" evaluation which coheres with the political care ethic, and with which to judge levels of care, is to interrogate "powerful processes through which some people and groups benefit and others lose out" (Everitt \& Hardiker, 1996:28). Interrogating what Everitt and Hardiker consider to be "corruption of care" would then provide an opportunity for alternative meanings (of care practices) to be articulated. The framework which Everitt and Hardiker propose for evaluating "good practice" is a deconstruction of "meanings of the practice" as a "value-laden and political process" (1996:25, 29). The Everitt and Hardiker framework also links with Fraser's (1989) argument on the norms and assumptions of welfare policy regarding how needs are differentially interpreted by different stakeholders.

"Good practice" principles are also useful as a means with which to evaluate and judge South African social, economic and political contexts of service delivery because, according to Everitt and Hardiker (1996:29), public service delivery plays a valuable role in reporting on the intended and unintended consequences of health, welfare and economic social policies. Here too the political care ethic and the politics of needs interpretation cohere with principles of "good practice", for all these frameworks consider the service user's perspective when analysing the impact of policy in social context and how well care is received.

"Good enough" practice also "detects and makes visible practice that is not so good", i.e. "corruption of care", as it fulfils an important role in generating evidence about service delivery and knowing about the practice and meaning of service delivery to users of services (Everitt \& Hardiker, 1996:29, 31). 
The authors make use of this framework incorporating the political ethics of care, politics of needs interpretation and "good enough practice" in order to provide a normative lens with which to judge how adequate Cape Town service users found service delivery to be in a study conducted by social work students at the University of the Western Cape.

\section{METHODOLOGY}

Service users' responses are drawn from questionnaires administered by 52 fourth-year social work students at the University of the Western Cape during 2005. Each of the 52 students administered five questionnaires to service users at their fieldwork placements as part of their final-year research project. Convenience sampling was used to administer these questionnaires, with students finding the first available service users at their placements to administer them to. The same students each undertook a participant observation study of service users' experiences at various organisations in the greater Cape Town metropole, where they were placed for their fieldwork education programme. In addition to the 260 questionnaires and 52 participant observation studies, each of the 52 students was required to do one qualitative interview with one service user at the same organisation. The organisations where students were placed represent the fields of health, welfare, development programmes, institutional care and protection services. The triangulated methods were conducted separately on successive Wednesdays spent at the public social service organisations. The questionnaires were preceded by participant observation studies and followed by qualitative interviews, which were tape recorded and transcribed by students themselves.

The main research aim for the questionnaires was to find out who uses the service; what kind of needs service users have; how service users experience the service given at the organisation; and how service users think services could be improved. For the participant observation study students had to observe what is happening in relation to service users by describing what is going on in service delivery. For the observations students were given guidelines for research questions, namely, how welcome do you think service users feel on entering the organisation; what would make them feel this way; how accessible is the organisation to the service user population; what is the predominant language used between service users and social workers; how long do service users have to wait before being attended to. Qualitative interviews were conversational and unstructured because students had to find out and get to know from service users what their views on, and experiences of, service delivery are.

The following section describes the results of the data by starting with who the service users are and their social location in Cape Town metropole in the Western Cape, South Africa.

\section{SERVICES USERS' IDENTITY AND SOCIAL CONTEXT}

In response to the research question "who uses the services", the following characteristics emerged about service users to whom questionnaires were administered:

Mainly female (66\%);

Xhosa $(32 \%)$;

Afrikaans (48\%) speaking;

Living with parents (28\%) and family other than parents $(21 \%)$ rather than in nuclear setups;

Urban $(69 \%)$ rather than rural $(31 \%)$;

Had an educational level of Grade 8 or lower $(50 \%)$;

Poor (no income - 37\%; R200-R499 per month - 11\%); and

Receiving a grant in household $(58 \%)$. 
As reported above on "who uses the services", service users need and directly depend on social welfare programmes, because of the structural condition of poverty in which they are socially located. The significance of their views and experiences of service delivery are discussed in the following section.

\section{INTERPRETING SERVICE USERS' EXPERIENCES WITH THE FRAMEWORK}

Service users have the right to legitimate opinions. Their voices as "full moral beings", as is evidenced, expose a practice of service delivery that holds benefits for some but not for others. The following quotation with which to open the research discussion is chosen from a student's transcription of a qualitative interview. The evidence of engaging in conversation with a service user clearly reflects a voice that spoke out strongly on service delivery, expressing powerlessness in the face of overwhelming adversity. As the intent of this case study is to reflect on service users' views and experiences as participatory responsiveness, we wish to foreground the particular issues which were raised in this interview.

"R: I just want to say that I hope that this is not just another interview, it [is] not to blackmail anyone or any institution or anybody, but that something will come out of it in the interest of the community of ...... I think employing more staff will sort of alleviate the problem ..... If... it... the people ... those in power can just come here, sit down have a look at what we as a community go through and without pointing fingers to any specific person, see what improvements can be made. Because we have been in a democratic South Africa for more than ten years now, we hear very nice promises and every time it is before the elections. After the elections it seems that those have forgotten us who have voted them into power...".

Generally, service users live in pockets of economically depressed communities with high levels of unemployment and resultant socio-economic social problems, for example, violent crime, lack of social housing, which impact negatively on peoples' lives. South African neoliberal economic policy holds limited prospects for employment opportunities in these communities as a result of the slow "trickle down" and emphasis on privatisation, which does not promote redistributive development (Allie, 2003:3). Instead, the policy militates against local and internal socio-economic redistribution for a new social order (Allie, 2003). Furthermore, Allie (2003:3) reports from the South African New Economic Network that a governmental review of the past ten years has shown that even more people live in destitution than in 1994 (the year in which the new government was elected). Sadly, it is these communities who voted in good faith for reconstruction and development with the hope that their lives would change for the better (Allie, 2003).

The new social order voted for by the majority of South Africans is premised on the notion of social justice. However, social welfare policy, coupled to the economic policy, intends to address poverty by aiming to reach "self-reliance" for service users (Finance Policy for Developmental Social Welfare Services, 1999; White Paper for Social Welfare, 1997). This value is contradictory to the political ethic of care notion of human interdependence, because self-reliance assumes the construction of service users as "failures", "other" and "dependent", therefore needing government intervention.

\section{"Good enough" service delivery}

One hundred and forty-nine service users' views and experiences of service delivery could be regarded as "good" based on the following responses which emerged from the students' questionnaires in relation to the research question: How you see the service given at this organisation?: 
"staff are organised in doing their work (100 responses); facilities at agency are good (4); social worker was attentive (29); programmes offered were positive(16)”.

To describe "good enough" service delivery in greater depth, the students conducted interviews with service users. The following example reflects on a service user's experience of accessing first one service delivery point and then another. She initially encountered negative experiences at a particular organisation, but then decided by herself to move to another service delivery point, where she received better treatment and services. Although determined to access those resources which she needed for herself and her family, she understood that social workers can only do their best and, like other service users, she does not have any unrealistic expectations of service delivery.

"...but here it is different, there is no delays, the people here are always willing to help .... You do not stand on a line for the whole day. These social workers do not even shout at you if maybe you forgot something that will help you, so that you can get the grant, for example, the identity document and some other things that are needed when you need to apply for the grant. ... An amazing thing that was done here is that they have listed everything that is needed in a piece of paper so that I could remember, I was told that I must come first thing to-morrow morning and there would be no delays. This will be very helpful for me. I will not go back and forth wasting money".

The recognition in the above paragraph that "social workers do not even shout at you if maybe you forgot something" is a sad indictment on abusive behaviour towards service users, which was also reported by Laakso and Drevdahl (2006), who conducted a qualitative study of interviews with 38 women who reported emotional and economic abuse both in the welfare system and their personal lives.

Service delivery was generally described as "good" by those service users who experienced an administrative system that was in place for them to access care. The ritualised process of welcoming and being directed to relevant offices as well as having a comfortable working environment in which to engage with a social worker encourages reciprocal participation and communication at the level of personal relations.

Another example is from a participant observation study which a student reported on while at a government service organisation. She was invited to sit in on this interview between a social worker and a service user.

“... clients look happy and welcomed in the organisation .... By their facial expression you can tell that they get the service they are expecting. The client shows that by participating without being pushed by the social worker.... The clients together with the social worker had a successful session because what the client was able to get help from the social worker. They have also planned another session for another day".

"Caring about", as illustrated by the above examples, suggests an awareness of, and attentiveness to, the needs as described by service users. Attentiveness is then followed through with responsibility, as it was possible for the respective social worker to act to meet the service user's needs. In this instance "taking care of" (responsibility) constitutes a caring morality, because the social worker acts in accordance with what service users are communicating about their lived experiences and needs. In this co-constructed meaning of lived experience and needs, the service users' vulnerable position and interdependence are acknowledged by both social worker and service user, enabling them to recognise how private woes are impacted on by public social problems. This is the integrity of care that Tronto (1993) argues for when the phases and 
moral values of attentiveness, responsibility and competence which constitute care are integrated as practice and therefore provide service delivery with a "standard" for an "integrated wellaccomplished act of care" (Barnes, 2006; Fraser, 1989; Sevenhuijsen, 1998; Tronto, 1993).

Explicit in Tronto's (1993) argument for the integrity of care is that care should be performed in a competent manner starting with the viewpoint of the other. The moral integrity of care is based on mutual commitment, because it always includes reciprocity whilst at the same time recognising that service users and social workers are differently positioned in social relations. Where service users' responses describe how the social worker has acted competently to meet needs, this indicates to them both that the social worker showed concern for the outcomes of service delivery at an interpersonal level.

However, there are service users who do not benefit from service delivery. Service users' experiences of service delivery that is "not so good" raises questions about the adequacy of care's integrity and "good practice" principles.

\section{"Not good enough" service delivery}

Service delivery that is described as "not so good" by 94 service users is illustrated by the following responses to questionnaires administered to service users in relation to the research question: "How you see the service given at this organisation":

"too long to wait for assistance (26), need to improve service delivery - need more resources (28); services are not easily accessible, i.e. long travelling distance to organisation (11), geographical location is inconvenient(7); need more home visits (2); need on-site visits for job creation programmes (2); social worker was unable to help me (9); lack in communication (9); facilities are not so good, i.e. special needs not accounted for (5); pleasant environment but staff conduct needs to improve (4); give more people access to organisational programmes, especially for income generating (2)".

Services are perceived to be "not so good" when service users experience service delivery at social service agencies as not meeting their described needs; where all levels of staff are not participating and communicating in a co-operative manner; and where resources to access care are inadequate. Service users gain the impression that service delivery is "not so good" when service users feel unwelcome; have long waiting hours before being attended to; where offices are too small, cold, lifeless and seen as "disorganised"; and where there is an uncomfortable working environment. In addition to this, being faced with conflict; where staff are overstretched; cope with too many service users; give only as much of their time as can be possibly allowed without resources to support their work, then service users describe services as "not so good".

Focusing on the qualitative interviews with service users conducted by students, one student who actively engaged with a service user on the purpose and experience of accessing a service organisation was given a pertinent response. As the aim for the student's research was to know what was happening in service delivery at that time, the student's question is linked to the research aim. Not all students asked this kind of question nor got as sound a response in regard to what is happening to service users in service delivery. Therefore this service user's response was chosen for authenticity as spoken to and transcribed by the student.

"I: Do you feel needs are met and do they attend to you quickly?

R: They take their time and they ask a lot of questions, I thought it is so unnecessary ... I think that their work .... So they must do that but I feel sometimes it's really unnecessary. Like that 
man yesterday he leave work eleven years ago and he had to go where he used to work.... If you are ready for pension deal with that no go back to school..... I feel that is so .... (silent).... We don't see any things ... that you can put your trust in and it's like there is not hope for me and that's all ... needs aren't met”.

This comment clearly resonates with Fraser's (1989:154-155) notion of the administrative element in which the service user's life situation is publicly subjected to scrutiny in order to conform to previously determined administrative criteria which are applied through means testing before such application and welfare rights will either be condoned or denied. Fraser's (1989) contention that the juridical element is linked with the administrative element in service delivery shows how social policies are executed to benefit some service users but not all, for example, those whose life situation does not conform to previously determined administrative criteria, as is seen in the above excerpt, where the service user had come to apply for a pension and was subjected to what she regarded as unnecessary interrogation.

Service users have different ideas of their own needs and do not necessarily want to be "passive recipients" of the "caring about" they receive (Fraser, 1989; Tronto, 1993). Conflict in social relations arise because there are different perceptions of how needs and the process for meeting needs should be met. Tronto's (1993) definitive position regarding care is that service delivery should be based on the concerns and needs of the "other", a service user as person in his/her own right, and by implication, that participatory parity should prevail in these interactions. When engaging and deliberating with a service user about needs to be addressed, then the starting point is the service user's perspective, taking into account their descriptions of their situated lives. Service users expect social workers to understand what their needs are.

When service users respond that needs were not attended to in the "caring about" phase, then "taking care of" leads to inaction and constitutes inadequate caring morality, resulting in lack of "care giving" in service delivery. In this instance the four phases and moral values of the care ethic are neither inter-related nor integrated.

The following example from a qualitative interview highlights a similar scenario faced by a service user:

\section{"I: Are services sufficient?}

R: Yes ... I am HIV+, must eat healthy diet, but how? We don't have money and we are not working ... Need to be at a certain stage of infection before qualifying for disability grant .... Am now applying for grant ... am worried ... CD4 count is down."

Here the service user describes her own vulnerability, but is powerless to prevent her needs from being re-interpreted.

In such instances where service users do not benefit directly from service delivery, it is as a result of their position of passive citizens, which places them face-to-face with the legal apparatus that is in operation in the welfare system denying them the social rights they ought to be entitled to. Service users have tried to construct meaning of their own lived experiences and needs, but face a double jeopardy when they are subjected to the juridical-administrative element, because their needs are re-translated into the legal and administrative matters of service delivery policy (Fraser, 1989:154-155). The previous interview excerpts in this section show that the two service users interviewed were somewhat disconcerted about the number of questions that had to be answered when applying for an Old Age Pension and Disability Grant and indicate how a service user is subjected to the administrative element of needs 
interpretation. Both service users' subject position is highlighted in their own words: "needs are not met" ... "am worried"... "eat a healthy diet". The service user has to conform to criteria defined by social welfare policy by explaining themselves to the social worker, only to have their needs re-interpreted as, for example, "must eat a healthy diet, but how?", thus personalising her economic circumstances and reinterpreting the situation as her responsibility. One service user was disgruntled about the social security application procedure. She was waiting for an answer, but does not trust the system. For her, her needs remain unaddressed. The other service user needs financial security to address her health needs and knows that she must eat a healthy diet, but does not have the means to do so.

Bureaucrats have the power to make decisions about needs without necessarily engaging and deliberating on needs with the service user.

The results of the study show that service users do petition their needs to social workers, but in doing so they need to conform to those criteria administratively defined by policy through the administration of means testing. It is only the bureaucratic institution which is empowered to decide on service users' claims. Implementing the political ethic of care to engage with a service user would be better practice, because the service user and social worker would co-construct the meaning of situated life experiences and needs, as well as co-construct possible solutions. This engagement is based on mutual commitment and understanding of asymmetrical reciprocity, which gives the social worker better insight to work from the perspective of the service user.

Specific responsibilities and authority regarding service delivery are delegated to social workers in their respective organisations. The care ethic responsibility is "to take care of" service users when facilitating with them their access to public resources so that their needs can be met. However, service users are differently positioned, not realising that their needs can be reinterpreted. Their perception of social workers "doing their best" describes their own vulnerability when being "taken care of" and being "cared for", and is formed by their own position of "other", not deserving of better treatment, often leaving them feeling disempowered. Social workers constructed as "doing their best" are examples of Amartya Sen's "small mercies" of gratitude, which helps a service user to barely survive, to merely hope for (Sen in Tronto, 1993:139).

As frontline workers, social service workers address those needs which have been determined as administrative criteria through policy procedures far removed from daily service delivery, but which have power to determine which needs will be attended to and which solutions will be adequate (Fraser, 1989; Sewpaul \& Holscher, 2004; Tronto, 1993). This is the "privilege enjoyed by the powerful" as they are able "to define needs in a way that suits them" (Tronto, 1993:140).

The following response illustrates resistance to needs re-interpretation in the context of social relations where "needs are translated into legal-administrative matters" (Fraser, 1989:154). This is another example of participant observation in action and is drawn from the triangulated methods used by the students. The observation reflects a student's clear description of what happened unexpectedly at a service organisation while doing the research study. The description was not orchestrated and honestly reported as experienced - as is required from a participant observation study.

"An incident occurred at the office, a man entered as the gate was not locked; he was looking for the welfare lady, so I referred him to Ms... She then asked how she could help and he just started ranting saying that he is hungry and it is due to them, that he cannot work because they 
declared him mentally ill .... They then gave him something to eat and he calmed down and left the office."

The service users' rage, conflict and resistance to service delivery describe not only the "detached" "caring about" received on a personal level, but also an expression against the underlying power and authority of social relations between a service user and a social worker which a service user experiences as powerful. The service user argued that his real needs for food security and employment were not addressed. Instead he was angry about his experience of service delivery and wanted his hunger and need for food security to be addressed; therefore he turned back to the welfare organisation, insisting on being helped.

Fraser's (1989:155) contention about the juridical-administrative-therapeutic (JAT) interlinking elements opens up the therapeutic moment of the modus operandi. The therapeutic diagnosis of "mentally ill" is, Fraser (1989:145) contends, the political therapeutic element of the JAT in which social welfare issues get framed and needs to be re-interpreted. It is here where service users are subjected to scrutiny of the "mental health" aspects of their lives. The politics of social work and those practice "theories" contributing to the therapeutic interpretation are based on "individualist-reformist views". Here the aim of service delivery is premised on creating a better "fit" between individual and society, rather than addressing structural social changes (Payne, 1997:4-5). Services are then delivered to make individual behavioural changes, thus constructing gender-political and political economic problems as individual, psychological problems (Fraser, 1989).

The politics of needs interpretation can be seen as linked to the political ethic of care framework in Fraser's (1989) contention that a service users is positioned as "dependent other", whose needs are not co-constructed but re-interpreted as the therapeutic element of the JAT. A lack of awareness of needs when "caring about" makes it impossible to act on meeting those needs when "taking care of", leaving no competence for "care giving". The resultant gap which arises from need interpretation means that the position of the service users from their perspective of vulnerability is not considered.

The political ethic of care moral framework of attentiveness, responsibility and competence encourages social workers to act in accordance to what service users are communicating about their needs that are unmet, because it focuses the attention, responsibility and competence of service delivery on both the impact on and response of the service user (Barnes, 2006:119; Tronto, 1993). Fraser's (1989:145) contention that what lies at the heart of the politics of needs interpretation is what service users themselves really need, and that their interpretations of needs should be the authoritative part of the process for service delivery. Everitt and Hardiker (1996:32) suggest that a social worker will take responsibility for ensuring "good practice" when openly engaging with a service user about his or her needs. In doing so, social workers do not neutralise needs, regard the service user as "other", apply rational-technical approaches to needs interpretation or dichotomise themselves and service users, nor should they create a "fit" by adapting the service users to their situated life experience.

Without an awareness of, and attention to, needs as constructed by service users, it is not possible to act responsibly and competently, as required by the political ethics of care, as service delivery offers a ritualised procedure for meeting needs. Turning public strife into private woes implies that real felt needs are not understood in the broader social political context of basic needs. In this process the lack of the integrity of care means that, in this context, service delivery cannot be judged as "morally admirable". 
For service users who experience that service delivery is "not so good", then, according to Everitt and Hardiker (1996), "corruption of care" is associated with the gap that exists when the official policy value statements and intentions are different from what happens in actual service delivery, i.e. the manner in which social workers have the power to condone or deny needs with regard to the "poorest of the poor". This is a consequence of service users not realising that needs are interpretations open to public scrutiny for analysis and critique (Fraser, 1989:154). Service users are positioned through the juridical-administrative-therapeutic element in ways that do not empower them. It personalises them as "cases" and so militates against their collective identification (Fraser, 1989:154; Young, 1994).

The extracts from students' accounts above demonstrate that "corruption of care" arises when service users are differently positioned in the care relationship and the balance of power, powerlessness and empowerment are "taken for granted" irrespective of administrative procedures, and where power denies access to resources. Service users then not only feel powerless to gain access to bureaucratic structures, but are also powerless to influence the structure to be more responsive to their needs. When accessing service delivery, service users tried to exercise agency and express their citizenship as a "right to care". Service users, although aware of their rights as citizens and their right to entitlement, were powerless to effect it for they hold a form of "passive citizenship" in which "the state pre-empts the power to define and satisfy peoples' needs" (Fraser, 1989:156). This is aptly expressed in the following quote from an in-depth interview conducted with a service user by a social work student: "well I know I have the right to complain, but many a times you get so despondent because it feels if you are fighting against a concrete wall. Nothing is being done so you just asking yourself what is the use of complaining...”.

Yet service users perceive that social workers have responsibility for the system: "where else must we go if they do not help us". In this instance there are service users who do expect social workers to mediate and advocate for a more responsive service delivery system demonstrating their accountability to and for them. This example from a service user's exasperation in relation to the service she has experienced does indicate that the best interests in care are neither discussed nor deliberated between social worker and service user, even though Batho Pele and other principle ethics endorse democratisation of power in service delivery (Tronto, 1993; Everitt \& Hardiker, 1996). Such practice often results in meeting what Everitt and Hardiker (1996:33) refer to as "secondary objectives", by which they mean that "good practice" requires debating, for example, about the purpose of addressing poverty. Social welfare management ought to encourage debate on different points of view on poverty, basic needs, social security and welfare rights, so that service delivery does not lose its mission and objectives to serve the "poorest of the poor".

When secondary objectives, i.e. routinised service delivery, to promote self-reliance "take over as aims", and without the resources needed to achieve these aims, then service delivery "loses its sense of purpose in terms of serving humanity and their social rights" (Everitt \& Hardiker, 1996:33). Furthermore, Everitt and Hardiker (1996) contend that in such instances the service user is then reliant on the commitment and values of the social worker on a personal level. The moral capabilities entrusted to responsibility, from a political ethic of care perspective, then become more useful as a process to engage the service user with the social worker to mutually establish what the goals for service delivery are in "caring about" and on how "taking care of" and "care giving" should proceed. It is in this instance that the care ethic extends beyond the 
practice of principle ethics and is also more than the need to conform to bureaucratic and professional obligations (Tronto, 1993).

Which caring needs receive which resources is one of the moral dilemmas of care. Tronto's (1993:133) argument regarding competence is that good care always requires a number of resources, for example, finance, skill, time and material goods; "intending to provide care, even accepting responsibility for it, but then failing to provide good care, means that in the end the need for care is not met". Here the moral value of competence is related to care giving.

In this case study, where service users clearly describe service delivery as "not so good", they also describe the conflict they experience between the phases of "caring about", "taking care of" and "care giving". Where insufficient resources are allocated to social workers to "care about", to "take care of" and for "care giving", such process of "taking care of" has no concern about outcomes or end result (Tronto, 1993). The lack of resources for service delivery highlights the judgment that care is not "well provided", because service delivery operates within the macro neoliberal political-economy, which seeks to liberate the South African economy, making it rather more amenable to the forces of globalisation. With neoliberalism the market is seen "to be the organising principle for all political, social and economic decisions" (Giroux, 2004:1). Welfare expenditure, generally, is regarded as creating dependence, even though the aim of eradicating poverty and inequality is foregrounded in policy documents such as the Finance Policy for Developmental Social Welfare Services. Regrettably, this document states that services are fundable only if they meet the aims and objectives in line with self-reliance, negating the importance and centrality of care and interdependence. It is acknowledged in this document that the welfare budget will remain inadequate and will never be able to address all needs (Sewpaul \& Holscher, 2004:78, 80). By providing inadequate public expenditure for public intervention, service delivery is devalued and this undermines the capacity for public service delivery: in "the discourse of neoliberalism, the notion of the public good is devalued" (Giroux, 2004:3).

Self-reliance principles and values, inculcated through adherence to neoliberalism, help shape societal perceptions for service delivery as they are coupled to broader socio-economic values of privatisation and profit, self support and independence. Societal perceptions of service delivery are that care is socially constituted on the basis of serving persons, who like the service users in this study, are purported to be helpless, dependent, a burden on the state. Because of these perceptions, care is reduced to a lesser value - insufficient resources are allocated and distributed, thereby marginalising and trivialising the role of service delivery (Tronto, 1993). These views support the service users' and societal perceptions that care is not at all times a social concern and is not a central feature of the human condition - something that we all need.

\section{DISCUSSION AND RECOMMENDATIONS}

The normative framework incorporating the politics of needs interpretation, the political ethics of care and good practice provides a useful analytical tool to expand our understanding of service users' experiences and place these experiences in a broader political and social context. The framework provides a lens through which to view possibilities for responsive and caring service provision for the needs of the most vulnerable service users. Furthermore, the framework amplifies the necessity of inclusion of the service user's voice in service delivery (Cornwall \& Gaventa, 2001a).

Worldwide, resistance to neoliberal social work can possibly create a paradigm shift for a more critical social work practice (Ferguson \& Lavalette, 2006). One base on which to build a social 
work of resistance, suggested by the authors Ferguson and Lavalette (2006), is the contribution made by service users' views and experiences of service delivery, which can be used as a means for change of social work practice. The significance of this contribution is that a new paradigm would include "genuine alliances between frontline workers and service users" (Ferguson \& Lavalette, 2006:314). A more critical practice for social work would involve redirecting it to a structural and caring practice which seeks alternative possibilities for harnessing the market resistance with which to bring about social changes. Social work does have the capacity to link the macro with the micro, or "public issues" and "private woes", and enable service users to articulate their views on their situations and their strategies for changing them (Ferguson \& Lavalette, 2006; Joans \& Gaventa, 2002; Vodde \& Galant, 2002).

Using the normative framework to analyse service users' perceptions of delivery in the Western Cape foregrounds the importance of social accountability, responsiveness, responsibility and care. The framework underscores the necessity of service users' participation in the design and delivery, as well as monitoring and evaluating, of services, thus being seen as social citizens (Cornwall \& Gaventa, 2001b; Joans \& Gaventa, 2002). South African social work practice needs to become more inclusive by strengthening attempts to involve service users in research, in social policy formation and implementation, and other means of active participation ensuring democratic governance.

\section{REFERENCES}

ALLIE, M. 2003. As inequalities grow, South Africa's poor question the power of the ballot. Available: http://www.globalpolicy.org/socecon/develop/democracy/2003/11safrica.htm.

BANKS, S. 2006. Ethics and values in social work ( $3^{\text {rd }}$ ed). Basingstoke: Palgrave Macmillan.

BARNES, M. 2006. Caring and social justice. Basingstoke: Palgrave.

BERESFORD, P., PAGE, L. \& STEVENS, A.1994. Changing the culture: involving service users in social work education CCETSW Paper 32.2. London: Central Council for Education and Training in Social Work.

BERESFORD, P. \& CROFT, S. 2004. Service users and practitioners reunited: the key component for social work reform. British Journal of Social Work, 34:53-68.

CARR, S. 2007. Participation, power, conflict and change: theorizing dynamics of service user participation in the social care system of England and Wales. Critical Social Policy, 27(2):266276.

CORNWALL, A. \& GAVENTA, G. 2001a. From users and choosers to makers and shapers: Repositioning participation in social policy. IDS Working Paper 127 Sussex: Institute of Development Studies.

CORNWALL, A. \& GAVENTA, G. 2001b. Bringing citizen voice and client focus into service delivery IDS Working Paper 138 Sussex: Institute of Development Studies.

EVERITT, A. \& HARDIKER, P. 1996. Evaluating for good practice. London: Macmillan.

FINANCE POLICY FOR DEVELOPMENTAL SOCIAL WELFARE SERVICES 1999. Financing Policy: Developmental Social Work Services, 26 March 1998.

FERGUSON, I. \& LAVALETTE, M. 2006. Globalisation and global justice - towards a social work of resistance. International Social Work, 49(3):309-318. 
FRASER, N. 1989. Unruly practices: power, discourse and gender in contemporary social theory. Cambridge: Polity Press.

GIROUX, H.A. 2004. Neoliberalism and the demise of democracy: resurrecting hope in dark times. Available: http://www.dissidentvoice.org/Aug04/Giroux0807.htm-34k-.

HANLEY, B. 2005. Research as empowerment? Report of a series of seminars organised by the Toronto group. New York: Joseph Rowntree Foundation.

JACKSON, H. 2002. AIDS Africa: continent in crisis. Harare: SA/AIDS.

JOANS, E. \& GAVENTA, J. 2002. Concepts of citizenship: a review. IDS Development Bibliography 19. Sussex: Institute of Development Studies.

LAAKSO, J.H. \& DREVDAHL, D.J. 2006. Women, abuse and the welfare bureaucracy. Affilia, 21:84-96.

LEVIN, E. 2004. Involving service users and carers in social work education. London: Social Care Institute for Excellence.

PAYNE, M.S. 1997. Modern social work theory: a critical introduction. London: Macmillan/Palgrave.

RECONSTRUCTION AND DEVELOPMENT ANC 1994. The RDP - a policy framework. Johannesburg: Umanyano Publications.

SEVENHUIJSEN, S. 1998. Citizenship and the ethics of care. Feminist considerations on justice, morality and politics. London and New York: Routledge.

SEWPAUL, V. \& HOLSCHER, D. 2004. Social work in times of neoliberalism. A postmodern discourse. Pretoria: Van Schaik Publishers.

SKIDMORE, R.A. 1994. Social work administration. Dynamic management and human relationships $\left(3^{\text {rd }}\right.$ ed). New Jersey: Pearson Education.

TRONTO, J. 1993. Moral boundaries. Towards a political argument for and political ethic of care. New York and London: Routledge.

VODDE, R. \& GALANT, J.P. 2002. Bridging the gap between micro and macro practice: large scale change and a unified model of narrative - deconstructive practice. Journal of Social Work Education, 38(3):439-458.

WHITE PAPER FOR SOCIAL WELFARE - MINISTRY FOR WELFARE AND POPULATION DEVELOPMENT. 1997. White Paper for Social Welfare: Principles, guidelines, recommendations, proposed policies and programmes for developmental social welfare in South Africa. Pretoria: Government Printers.

WHITE PAPER, TRANSFORMATION OF PUBLIC SERVICE DELIVERY - MINISTRY FOR PUBLIC SERVICE 1997. White Paper on Transforming Public Service Delivery. Pretoria: Government Printers.

YOUNG, I.M. 1994. Punishment, treatment, empowerment: three approaches to policy for pregnant addicts. Feminist, 20(1):33-57.

Professor Vivienne Bozalek, Head, Department of Social Work, University of the Western Cape; Ms Wesley Lambert, Social Work Fourth Year Course Coordinator, University of the Western Cape, Bellville, South Africa 